\title{
ANNOUNCEMENTS OF THE FOUNDATION FOR THE DEVELOPMENT OF INTERNATIONAL LAW IN ASIA
}

\section{Sata Prize}

A separate announcement on the Sata Prize 2004 is to be found on the next page.

\section{Translation of writings in Asian languages}

In pursuing its aims the DILA Foundation invites proposals for the translation into English and the publication in the Asian Yearbook of International Law of essays of an outstanding character on topics of international law that are written/published in an Asian language. The Foundation has especially in mind writings of high quality whose dissemination to a wider public is to be considered of the highest interest and particularly useful for the promotion of the discussion of international law.

The writings should as a rule be estimated at no longer than 40 pages in print in the English version. The proposals need not necessarily come from the author him/herself and are to be accompanied by a short explanation and a brief summary in English of the contents of the essay concerned.

A Translation Committee of the Foundation, including the General Editors of the Yearbook, will decide on the proposals.

The Foundation will take responsibility for the costs of translation and, wherever necessary, those of linguistic revision. No translated version of the original text will be published in the Yearbook without the consent of the author and the copyright holder.

Proposals should be sent to the Editorial address of the Asian Yearbook of International Law, as indicated in the General Information, supra. 